\title{
РАСПРОСТРАНЕННОСТЬ ДИСЛИПИДЕМИЙ У ПАЦИЕНТОВ С НАРУШЕНИЯМИ УГЛЕВОДНОГО ОБМЕНА ПО ДАННЫМ РЕГИСТРА САХАРНОГО ДИАБЕТА В ТЮМЕНСКОЙ ОБЛАСТИ
}

\author{
²Бельчикова Л.Н., 'Суплотова Л.А., ${ }^{2}$ Рожнова Н.А., ${ }^{2}$ Бокова В.В. \\ 'ФГБОУ ВО «ТюмГМУ» Минздрава России, Тюмень \\ 2ГБУз ТО «Областная клиническая больница №1», Тюмень
}

\begin{abstract}
АКТУАЛЬНОСТЬ: дислипидемия является одним из важных факторов в развитии атеросклероза и сердечно-сосудистых заболеваний (ССЗ) у больных сахарным диабетом (СД). В мире сердечно-сосудистые заболевания занимают лидирующие позиции в причинах смертности. По прогнозам экспертов ВОЗ, к 2030 г. смертность от ССЗ увеличится до 23,6 млн.
\end{abstract}

ЦЕЛЬ: оценить частоту распространенности дислипидемий у пациентов с нарушением углеводного обмена в Тюменской области (ТО).

МАТЕРИАЛЫ И МЕТОДЫ: по данным региональной базы Федерального регистра сахарного диабета Тюменской области проанализированы такие показатели распространенности дислипидемии, как значения липидов крови - липопротеиды низкой плотности (ЛПНП), липопротеиды высокой плотности (ЛПВП) за 2019 г. Статистическая обработка результатов проводилась с помощью программы Statistica 10.

РЕЗУЛЬТАТЫ: в Тюменской области, как и в РФ, отмечен рост распространенности нарушений углеводного обмена, в большей степени за счет СД 2 типа (СД2). Общее число пациентов с СД за последние 5 лет увеличилось в 1,5 раза и к концу 2019 г. достигло 56 489. Только 46,9\% пациентов с СД 1 типа (СД1) имели показатели ЛПНП менее 2,5 ммоль/л; данный показатель у пациентов с СД2 был еще ниже и составил соответственно всего 45,3\%. В группе пациентов с нарушенной толерантностью к углеводам (НТГ) и с нарушенной гликемией натощак $(\mathrm{HГH})$ эти же показатели также представлены низкими значениями: 40,2\% и 34\% соответственно. В мужской популяции пациентов с СД показатели ЛПВП > 1 ммоль/л отмечены в 40,3\% при СД1 и в 18,7\% случаев при СД2. Среди пациентов с НТГ и НГН соответственно в 11 и 25\%. В женской популяции пациентов с СД показатели ЛПВП > 1,3 ммоль/л зарегистрированы при СД1 у 28,6\%, при СД2 - у 23,8\%. Среди женщин с НТГ и НГН данный показатель составил соответственно 37 и 20\%.

ВЫВОдЫ: распространенность дислипидемий среди пациентов с СД в Тюменской области характеризуется высокой частотой, что требует усиления лечебной тактики в плане коррекции дислипидемий. Распространенность дислипидемий у мужчин и женщин имеет гендерные различия с преобладанием дислипидемий в мужской популяции пациентов с нарушениями углеводного обмена.

КЛЮЧЕВЫЕ СЛОВА: сахарный диабет 1 munа; сахарный диабет 2 типа; нарушенная толерантность к углеводам; нарушенная гликемия натощак; дислипидемия. 